\title{
Diagnóstico da raiva em morcegos não hematófagos na cidade de Campo Grande, Mato Grosso do Sul, Centro Oeste do Brasil: descrição de casos
}

\section{Diagnosis of rabies in nonhematophagous bats in Campo Grande City, Mato Grosso do Sul Centro Oeste do Brazil: report cases}

\author{
Gisele Torres de Deus ${ }^{1}$; Meire Becer ${ }^{2}$; Italmar Teodorico Navarro ${ }^{3 *}$
}

\section{Resumo}

\begin{abstract}
Alterações ecológicas nos ecossistemas silvestres tem contribuído significativamente para o aumento das colônias de morcegos não hematófagos no perímetro urbano. O presente trabalho tem por objetivo, descrever casos de raiva em morcegos não hematófagos no perímetro urbano de Campo Grande-MSBrasil. No período de fevereiro a dezembro de 2001, foram estudados 526 morcegos não hematófagos. Amostras de sangue foram e tecido, de cada animal, que foram submetidas as provas de imunofluorescência direta (IFD) e prova biológica (inoculação em camundongos), para pesquisa do vírus rábico. De todas amostras examinadas, seis foram positivas para o vírus da raivas $(1,13 \%)$, sendo três de morcegos frugívoros e três de insetívoros. Entre os morcegos frugívoros identificados, registra-se o Artibeus fimbriatus, sendo a primeira descrição desta espécie na cidade de Campo Grande e o primeiro caso de raiva citado na literatura científica nesta espécie, no Brasil.
\end{abstract}

Palavras-chave: Raiva, morcegos, vírus, diagnóstico.

\begin{abstract}
Ecological alterations in the environment may have contributed significantly for the increase of nonhematophagous bats in urban perimeter. This migration has also brought the virus into the cities. This work aimed to describe rabies cases in bats caught from the urban areas of Campo Grande, Mato Gorsso do Sul - Center West Brazil. During the period of February the December of 2001, a total 526 bats were sent for rabies diagnosis. After the identification and classification of bats, fragments of brain, salivary gland and interscapular brown fat collected from each animal were submitted for direct fluorescent antibody (dFA) test and mouse inoculation test (MIT) for rabies diagnosis. Among the 526 sample examined, six $(1.13 \%)$ were found positive for rabies by the both tests, and of theses, three belonged to insectivorous bats and the other three, frugivorous bats. Among the frugivorous bats, one was identified as the Artibeus fimbriatus. The presence of this species had never been reported in the city of Campo Grande, and this is also the first report of rabies in this species in our country.
\end{abstract}

Key words: Rabies, bats, virus, diagnosis.

\footnotetext{
1 Medico Veterinário do Centro de Controle de Zoonoses de Campo Grande-MS, Pós Graduando do Curso de Saúde Pública e Ação Comunitária pelo INBRAPE e Universidade Para o Desenvolvimento do Pantanal (UNIDERP), Campo Grande-MS.

2 Farmacêutico e Bioquímico, Pós Graduando do curso de Saúde Pública e Ação Comunitária pelo INBRAPE e Universidade Para o Desenvolvimento do Pantanal (UNIDERP),, Campo Grande-MS.

3 Médico Veterinário, Professor Doutor do Departamento de Medicina Veterinária Preventiva/ Universidade Estadual de Londrina (UEL)-PR. Endereço para correspondência e pedidos de separatas: CP. 6001, CEP 86.051-990, Londrina-PR, e-mail: italmar@uel.br

* Autor para correspondência.
} 


\section{Introdução}

Os morcegos reúnem particularidades ímpares entre os animais. São os únicos mamíferos que voam, podem hibernar, longíveros, vivem em todos os continentes, com exceção dos pólos. Pode atravessar barreiras geográficas, pela migração natural para busca de alimento ou para fugir do frio. Nas Américas essa preocupação sempre foi maior, frente à existência de espécies hematófagas, as quais, como elo na cadeia de transmissão, desempenham um importante papel na raiva dos herbívoros (MORCEGOS, 1998).

Considerando que o controle de raiva entre os animais urbanos (cães e gatos) vem sendo cada vez mais eficiente, e as medidas na área rural junto aos animais de interesse econômico também vêm se aprimorando, os animais silvestres e os sinantrópicos assumem um papel de extrema importância como reservatórios naturais do vírus rábico. Este fato já ocorre nos países, onde a raiva nos animais domésticos foi controlada (ELKHOURY et al., 1998).

Dentre as espécies na natureza, os quirópteros, pelas suas particularidades biológicas, têm sido objeto de estudos e pesquisas na busca de um melhor entendimento do seu papel na manutenção e transmissão da raiva (LEITE, 1999).

Assim, o progressivo controle da raiva, particularmente a canina, e a conseqüente redução da raiva humana, transmitida pelo cão, está colocando cada vez mais em evidência a importância da raiva em morcegos e em outros animais silvestre (TAKAOKA, 1996; LEITE, 1999). No estado de São Paulo morcegos já ocupam o segundo lugar como transmissores da raiva para os seres humanos (TAKAOKA; OMATA, 2001)

É preocupante o crescente aumento da população de morcegos no perímetro urbano de Campo GrandeMS, em virtude do desmatamento da região ou da migração para busca de alimento. Assim o presente trabalho tem por objetivo levantar e descrever os casos de raiva em morcegos não hematófagos, ocorridos na cidade.

\section{Material e Métodos}

No período de fevereiro a dezembro de 2001 o Centro de Controle de Zoonoses (CCZ) de Campo Grande-MS, recebeu 529 exemplares de morcegos não hematófagos com suspeita de raiva. Os animais foram enviados a Agencia de Inspeção e Defesa Agropecuária (IAGRO)-MS, para exame de pesquisa de vírus rábico, segundo a técnica de imunofluorescência direta (IFD) e prova biológica ( inoculação em camundongo).

\section{Identificação dos Exemplares}

Após a colheita do material (cérebro, glândulas salivares e tecido adiposo interescapular) para diagnóstico do vírus rábico os exemplares foram encaminhado ao CCZ de São Paulo-SP, para a classificação segundo a alimentação principal e a identificação da família, da espécie e do gênero (VIZOTTO; TADDEI, 1973).

\section{Imunofluorescência Direta}

A técnica de imunofluorescência indireta foi empregada para examinar amostras do cérebro, glândulas salivares e tecido adiposo interescapular (WORLD HEALTH ORGANIZATION, 1992).

\section{Prova Biológica}

As amostras de cérebro, glândula salivar e tecido adiposo interescapular dos morcegos foram processadas e inoculadas via intracerebral em camundongos albinos, procedentes do biotério do IAGRO Campo Grande/MS, com 21 dias de idade e 12 gramas de peso. Após a inoculação os camundongos foram observados por 21 dias, conforme protocolo do (WORLD HEALTH ORGANIZATION, 1992). 


\section{Resultado e Descrição dos Casos}

Os seis casos de raiva em morcegos não hematófagos identificados ao redor de Campo Grande - MS, $(1,13 \%)$ demonstra a disseminação do vírus em diferentes pontos da cidade.

\section{$1^{\circ}$ Caso}

No dia 21 de fevereiro de 2001, por volta das 16:00 horas, foi encontrado um morcego prostrado, no chão da residência no distrito oeste da cidade. $\mathrm{O}$ exemplar foi classificado como, macho da família Molossidae, não sendo possível a identificação da espécie.

O diagnóstico foi positivo para raiva pela IFD e na prova de inoculação intracerebral em camundongos, apresentando período de incubação médio de 12 dias.

\section{$2^{\circ}$ Caso}

No dia 13 de maio de 2001, por volta das 5:00 horas da manhã, foi encontrado um morcego morto, na calçada de uma residência, no distrito norte, zona urbana. $\mathrm{O}$ exemplar foi identificado como sendo macho, jovem, da família Phyllostomidae e espécie Artibeus fimbriatus, morcego frugívoro, peso 39 gramas.

O diagnóstico foi positivo para raiva pela IFD e na prova de inoculação em camundongos, com período de incubação médio de 7 dias.

\section{$3^{\circ}$ Caso}

No dia 24 de maio de 2001, às 7:40 horas, foi encontrado um morcego morto no quintal de uma residência, no distrito norte da cidade. O exemplar foi identificado como sendo macho adulto, da família Vespertillonidae, e espécie Mycotis nigricans, morcego insetívoro, peso 4 gramas.

O diagnóstico foi positivo para raiva pela IFD e prova de inoculação em camundongos, com período de incubação de 17 dias.

\section{$4^{\circ}$ Caso}

No dia 23 de maio 2001, por volta da 9:30 horas da manhã, foi encontrado morto na garagem de um estabelecimento, no distrito central da cidade. $\mathrm{O}$ exemplar foi identificado como macho, da família Phyllostomidae, não sendo possível a classificação da espécie.

O diagnóstico foi positivo para raiva pela IFD e na prova de inoculação em camundongos, com período de incubação de 15 dias.

\section{$5^{\circ}$ Caso}

No dia 12 de junho de 2001, por volta das 10:00 horas da manhã, foi encontrado um morcego prostrado, no distrito sul, da cidade. Sendo o único exemplar capturado pela equipe do Centro de Controle de Zoonoses (CCZ) e enviado para pesquisa. O exemplar foi identificado como fêmea adulta, da família Molossidae e espécie Nyctinomops laticaudatus, morcego insetívoro, peso 8 gamas.

O diagnóstico foi positivo para raiva pela IFD e prova de inoculação em camundongos, com período de incubação de 13 dias.

\section{$6^{\circ}$ Caso}

No dia 17 de julho de 2001, por volta das 9:00 horas da manhã, foi encontrado um morcego no quintal de uma residência, no distrito oeste da cidade. Tratava-se de um adulto fêmea, da família Phyllostomidae e epécie Artibeus lituratus, morcego frugívoro, peso 62 grs.

O diagnóstico foi positivo para raiva pela IFD e na prova de inoculação em camundongos, com período de incubação de 11 dias.

\section{Discussão}

Após a ocorrência do primeiro caso no dia 22 de fevereiro de 2001 ter sido amplamente divulgado na imprensa, houve o recebimento, pelo Centro de 
Controle de Zoonoses da cidade de Campo Grande MS, de um grande número de exemplares suspeitos de raiva totalizando 529 morcegos não hematófagos examinados em 2001. Destes, seis $(1,13 \%)$ casos foram positivos para raiva, que está dentro do esperado para ocorrência dessa infecção em morcegos não hematófagos (UIEDA; HARMANI; BRANDÃO, 1995).

Dos morcegos positivos, dois foram encontrados ainda prostrados e vivos, e quatro mortos, em locais não habituais (chão de residência, quintal, varanda, garagem, em baixo de uma árvore). Os morcegos tinham sido colhidos de diferentes pontos do perímetro urbano e peri-urbano.

Dos casos encontrados vivos, os horários em que foram observados também não correspondiam com o comportamento habitual para suas atividades fora dos abrigos (entre 10:00 e 16:00 horas). Uieda; Harmani e Brandão (1995) afirmam que está característica pode ser considerada como um sintoma de estado doentio do animal, suspeito de raiva. Estes achados, presença em horários e locais não habituais, observados nos seis exemplares e o estado de paralisia em 2 exemplares, também esta de acordo com os observados por Uieda et al. (1996). Constantine (1979) verificou que 63\% dos morcegos infectados pelo vírus da raiva apresentavam-se paralíticos ou doentes, contra apenas 30\% dos observados em Campo Grande. Nesta condição de paralisia ou doente, as chances de ocorrer agressão humana acidental (envolvendo principalmente crianças) e ou agressão em animais de estimação (cães e gatos), causada por um morcego raivoso são remotas, segundo Constantine (1979), mas não podem ser desprezadas.

Dos seis exemplares positivos para raiva, três eram frugívoros e três insetívoros. Esses achados estão de acordo com Uieda et al. (1992) que afirmam que esta espécie de morcego não hematófago, encontra nas cidades condições favoráveis para sua permanência, devido a grande oferta de abrigos e alimentos, tanto nas plantas utilizadas no paisagismo como nas exploradas como fonte de alimento. Da mesma forma que os edifícios são utilizados como abrigo durante o dia, a noite, a iluminação artificial das cidades atrai insetos que são habitual alimento dos morcegos.

Dois grupos de morcegos segundo Martorelli (1995), foram particularmente favorecidos, os insetívoros e os fitófagos ( frugívoros e nectarivoros). Seguindo essa tendência o número destes animais na área urbana de Campo Grande - MS tem aumentado significativamente nos últimos anos. Essa transição epidemiológica exigirá esforços adicionais de investigação para o desenvolvimento de novas técnicas e estratégias de controle da raiva (TAKAOKA; OMATA, 2001; UIEDA et al., 1996).

A distribuição dos casos de raiva em morcegos não hematófagos na cidade de Campo Grande foi homogênea, na localização e período do ano. Sendo encontrado em quatro pontos eqüidistantes da cidade e nas estações: verão, outono e inverno. Autores como Uieda, Harmani e Brandão (1995) Uieda et al. (1996) e Passos et al. (1998) e Passos (1999), descreveram casos isolados de raiva em morcegos não hematófagos, não apontando um período do ano ou local específico de ocorrência. Contrariando esses autores, Burns e Farinacci (1955), descreveram surtos de raiva em morcegos não hematófagos, com cinco casos no período de 30 dias oriundos de uma colônia de Tadarida brasiensis.

Uieda et al. (1996) afirmam que a correta identificação da espécie é fundamental, pois cada uma apresenta características biológicas peculiares, que são importantes na avaliação preliminar da situação encontrada. A separação de morcegos em apenas dois grupos (hematófagos e não hematófagos) tem dificultado o estudo de revisão e analise dos dados oficiais, prejudicando, desse modo, o conhecimento do papel das espécies na epidemiologia da raiva.

Dos seis exemplares, infectados pelo vírus rábico, em apenas quatro foi possível a identificação, sendo uma de espécie Artibeus fimbriatus, uma Myotis 
nigricans, já descrito por Martorelli (1995) como hospedeiro do vírus rábico, uma Nyctinomops laticaudatus, descrito por Uieda, Harmani e Brandão (1995), e uma Artibeus lituratus, descrito primeiramente por Torres e Lima (1935), e posteriormente por Silva e Silva (1974), Uieda et al. (1992) e Passos (1999).

Este é o primeiro registro da raiva na espécie Artibeus fimbriatus no Brasil, igualmente inédito no município de Campo Grande-MS .

\section{Conclusões}

Os seis casos de raiva em morcegos não hematófagos identificados ao redor de Campo Grande - MS, $(1,13 \%)$ demonstra a disseminação do vírus em diferentes espécies de morcegos e, embora a raiva canina esteja controlada, o vírus está circulante nos morcegos do perímetro urbano.

Os casos positivos para raiva não apresentaram predileção por estação do ano, tipo de colônia ou localização particular na cidade.

Foi identificada uma nova espécie de morcego não hematófago, infectado pelo vírus rábico, na cidade de Campo Grande

\section{Recomendações e Considerações Finais}

É importante que ações educativas sejam feitas, no sentido de esclarecer a população sobre a importância dos morcegos para o meio ambiente e também sobre os riscos que estes animais podem oferecer quando apresentam alterações de comportamento. Deve haver uma grande integração dos serviços de atendimento médico e médico veterinário, para atuar no sentido de prevenção e profilaxia da raiva.

\section{Referência}

BURNS, K. F.; FARINACCI, C. J. Rabies in nonsanguivorous bats of Texas. Journal of Infectious Diseases, Chicago, v.97, p.11-18, 1955.

CONSTANTINE, D.G. Bat rabies and bat management. Bulletin of the Society for Vector Ecology, Santa Ana, v.4, p.1-9, 1979.

ELKHOURY, M. R.; SILVA JUNIOR, J .B.; OLIVEIRA, R. C.; ARAUJO, F. A. A. Raiva humana transmitida por morcegos no Brasil,1998-2000. In: SEMINÁRIO INTERNACIONAL MORCEGOS COMO TRANSMISSORES DA RAIVA, 2001, São Paulo. Programa e resumos... São Paulo: Parlamento Latino Americano, Memorial da América Latina, 2001.

LEITE, P.A. Manual dos morcegos da região de Campo Grande, Estado do Mato Grosso do Sul, com ênfase para as espécies urbanas. Circular Técnica, Campo Grande, v.3, n.2, p.113-129,1999.

MARTORELLI, L. F. A. Isolamento do vírus rábico de morcego insetívoro Myotis nigricans. Revista Saúde Pública, São Paulo, v. 29, p.140-141, 1995.

PASSOS, E.C.; CARRIERI, M. L.; DAINOVSKAS, E.; CAMARA, M.; SILVA, M. M. S. Isolamento do vírus rábico em morcego insetívoro, Nyctinomops macrotis, no município de Diadema, SP (Brasil). Revista de Saúde Pública, São Paulo, v.3, n.1, p.74-76, 1998.

PASSOS,C. E. Vírus rábico isolado de morcego frugívoro (Artibeus lituratus), capturado em 1997 no município de Rio Claro -São Paulo. Revista de Saúde Pública, São Paulo, v.4, n.1, p.75-76, 1999.

SILVA, N. M.; SILVA, R. A. Ocorrência do vírus da raiva em morgegos frugívoros Artibeus lituratus (Olfers, 1818). In: CONGRESSO BRASILEIRO DE MEDICINA VETERINÁRIA, 14., 1974, São Paulo. Anais... São Paulo: [s.n.], 1974. p.102.

TAKAOKA, N. Y. Considerações sobre a raiva humana transmitida por quirópteros no Estado de São Paulo. Boletim Instituto Pasteur, São Paulo, v.1, n.2, p.59-61, 1996

TAKAOKA, N.Y.; OMATA, T. M. Raiva humana transmitida por morcegos no estado de São Paulo, Brasil. In: SEMINÁRIO INTERNACIONAL MORCEGOS COMO TRANSMISSORES DA RAIVA, 1998, São Paulo. Programa e resumos... São Paulo: Parlamento Latino Americano, 2001.

TORRES, S.; LIMA, E. Q. A raiva e sua transmissão por morcegos hematophagos e infectados naturalmente. Revista Departamento Nacional Produção Animal, Rio de Janeiro, v.2, p.1-55, 1935. 
UIEDA, W.; HARMANI, N. M. S.; BRANDÃO, M. M.; AGUIAR, E. A. C. Morcegos hematófagos: 2.um indivíduo macho adulto no centro da cidade de São Paulo. In: SEMINARIO NACIONAL DE RAIVA, 1., 1992, São Paulo. Anais... São Paulo: [s.n.], 1992.

UIEDA, W.; HARMANI, N. M. S.; BRANDÃO, R. Raiva em morcegos insetívoros (Molossidae) do Sudeste do Brasil. Revista Saúde Pública, São Paulo, v.29, p.393397, 1995.
UIEDA, W.; HAYASHI, M. M.; GOMES, L. H.; SILVA, M. M. S. Espécies de quirópteros diagnosticadas com raiva no Brasil. Boletim do Instituto Pasteur, São Paulo, v.1, p.17-35, 1996.

VIZOTTO, L. D.; TADDEI, V. A. Chave para determinação de quirópteros brasileiros. Revista da Faculdade de Filosofia Ciências e Letras de São José do Rio Preto, São José do Rio Preto, v.1, p.1-72, 1973.

WORLD HEALTH ORGANIZATION. Expert Committee on Rabies, $8^{\text {th }}$ Report. Geneve, 1992. (Technical Report series, n. 824). 